\title{
Examining Interdependencies and Constraints in Co-Creation
}

\author{
Bran Knowles, Christopher N. Bull, Nigel Davies, Will Simm, Oliver Bates and Niall Hayes \\ Lancaster University \\ Lancaster, UK \\ [b.h.knowles1, c.bull, n.a.davies, w.a.simm, o.bates, and n.hayes]@lancaster.ac.uk
}

\begin{abstract}
This paper reports on the first year of a three-year-long cocreation project with older adults. We focus our analysis on one particular workshop in which participants stopped designing and began to think about promoting the app we were co-creating. The workshop proved uniquely important for examining assumptions we had made about how and why the co-creation process would be successful. This paper concedes flaws in these assumptions and in the execution of the methodology as a way of illuminating dynamics that act on research projects in ways that are antithetical to effective co-creation. Reporting on the unexpected results of our participant engagements, we reveal new insights into the challenges in executing co-creation methodology.
\end{abstract}

\section{Author Keywords}

Co-creation; co-design; participatory design; older adults; aging; ageing; adoption; deployment; customer development

\section{INTRODUCTION}

For the majority of adults, advancements in mobile and digital technology have been embraced in large part because they afford new ways of accomplishing activities of daily living that are more efficient. While there is significant variability among older adults in terms of their technology use and literacy [24], older adults are less likely to embrace these tools [37], and many actively resist adopting them [26]. In light of this apparent digital divide, there is growing concern about the ability of those individuals eschewing digital technologies to remain independent into their old age [10], particularly as more and more essential government services move to online only format.

Until fairly recently, HCI has focused on compensating for issues pertaining to age related decline in designing for older adults [34, 40], approaching aging as an accessibility and usability challenge. And yet, non-use is rarely fully explained by difficulties in using these technologies [26]. To the contrary,

Permission to make digital or hard copies of all or part of this work for personal or classroom use is granted without fee provided that copies are not made or distributed for profit or commercial advantage and that copies bear this notice and the full citation on the first page. Copyrights for components of this work owned by others than ACM must be honored. Abstracting with credit is permitted. To copy otherwise, or republish, to post on servers or to redistribute to lists, requires prior specific permission and/or a fee. Request permissions from permissions@acm.org.

DIS '19, June 23-28, 2019, San Diego, CA, USA

(C) 2019 ACM. ISBN 978-1-4503-5850-7/19/06 . . 15.00

DOI: https : //doi .org/10.1145/3322276. 3322317 when older adults find technology to be useful they can be highly resourceful in finding ways of overcoming difficulties in using it $[27,21,47]$. This suggests that when older adults reject mobile and digital technologies it is partly because they do not perceive great enough overall benefit in adopting them $[27,26,43]$.

One reason perceived usefulness of mobile and digital technologies is low for older adults is that few of these tools are designed with them in mind [4, 23, 40, 43]; but older adults also consistently reject tools designed specifically for them $[22,43]$. One proposed means of garnering buy-in from older adult end-users is instead to consult with them throughout the design process [23, 34]; and indeed many studies have confirmed that older adults are willing and eager to take part in the creation of new technologies that add value to their lives [8, 31, 34, 42].

In this paper we report on a project called Mobile Age, which aimed to produce mobile applications that help older adults easily and efficiently access public services in order to promote independent living. Hoping to produce apps that older adults will actually want to use, the project actively engaged them as participants in the design process. To this end, we adopted a co-creation methodology comprising interviews and an extensive series of workshops, one of which we choose as the focus of our analysis for this paper. Recognizing the difficulties we experienced in reaching our target users in the recruitment stage of the project, we conceived of an App Promotion workshop as a bolt-on to our original plan whereby we might leverage our participants' influence among and expertise regarding their peers as a way of increasing uptake of the app in the community-i.e. making de facto user champions of our participants. Specifically, the workshop was designed to enable participants to co-create a strategy for promoting the first of our co-created applications, the Events app, and the discussion was planned to elicit ideas regarding which particular individuals to target in the community, how to reach them, and how to persuade them to use the app.

Pivoting to the challenge of promoting the app proved an effective means of enabling a more critical view on what we had been co-creating. To our surprise, this workshop exposed the flawed assumptions that had been guiding our app design as well as the flawed assumptions guiding our co-creation process. Among these, we found that 1) despite having actively shaped the design, participants were demonstrably confused about 
what the app would be; 2) the mere fact of having helped design an app does not mean the participants thought it was a good idea; and 3) promoting an application as a user champion requires a certain skill set and attitude to technology that may not come naturally to all, particularly to older adults.

As relevant context for this work, we note the growing trend toward funding bodies (at least in the UK) requiring that projects include an element of co-creation with stakeholders at the grant writing stage. Even though the call that Mobile Age was funded under did not require co-creation at any stage, we had assumed that working with the stakeholders early on would help us scope the domain so that when we started the project we were already heading in a sensible direction. Contrary to expectations, we found that co-creating the grant proposal with stakeholders does not guarantee a smooth path through co-designing with participants for two reasons. Firstly, doing so creates an additional set of stakeholder expectations that impact on the co-design in ways that are not necessarily visible to participants, thereby contributing to mismatches in expectations between participant-users and researcher-developers. Secondly, where there are flaws in the initial scoping done with stakeholders, engaging with individuals in the co-design stage is an essential corrective force; but it can take a surprisingly long time to get to the point where researchers are able understand the adjustments that need to be made, and project timescales may not easily accommodate these long learning curves. This suggests that the work of co-creating a research project ought to be conceived of as ongoing beyond the grant writing stage: opportunities to pivot need to be built into the research plan to elicit reflection on the project's scope, and sufficient time needs to be budgeted to comfortably accommodate re-scoping.

We offer this work in the tradition of other critical, selfreflexive accounts that aim to advance participatory and cocreation research methodology (e.g. [5, 6, 11, 45]). By examining our own mistakes we identify dynamics-such as the formalization of project objectives, the influence of stakeholder framings, the desire to please invested parties, and sheer project momentum - that need attending to in order to insulate co-creation projects from failure.

\section{OUR CO-CREATION PROCESS}

In attempting to understand what users need, HCI researchers commonly engage with prospective or representative users [13] so that they might "learn something we didn't know we needed to know" [32] and hence develop more "robust and sustainable design outcomes" [28]. Techniques for undertaking these investigations are myriad, though generally occurring within facilitated participant workshops of one kind or another. In light of the fact that facilitation is hard to do well $[3,45]$ but also greatly impacts the outcomes of these engagements $[9,12]$, there have been numerous calls for better accounting of the inherent messiness that transpires during participatory projects $[7,29,36,39]$. Further, recognizing the responsibility that comes from involving individuals in research projects [25, 46], additional ethically-minded criteria have been proposed for evaluating the success of participatory outcomes, including: some accounting of what participants (and other stakeholders, researchers included) gain from the engagement $[2,6,13,20$, 39]; and examination of the true extent of democratization of the design process $[20,39,46]$.

In talking about our methodology, we adopt the term cocreation [18]. We understand our approach as building on the body of work in co-design and participatory design [35] and using techniques inspired by action research [25] and agile methodologies (http://agilemanifesto.org) to engage end users in scoping the project, ideating and developing prototypes. ${ }^{1}$ Below we describe the agendas and commitments that defined the project parameters, summarize the project's various phases of research (shown by Figure 1), report the participant recruitment strategy, and explore the evolution of the concept of the Events app.

\section{A Priori Commitments}

Vines et al. [39] argue that participatory projects configure participation in accordance with a priori agendas (see also [29]), and that researchers ought to be more transparent about these agendas in their reporting. To this end, we report below our a priori commitments.

This work was funded as an EU Horizon2020 "innovation action." Such calls are, "directly aiming at producing plans and arrangements or designs for new, altered or improved products, processes or services" [14]. The stated objectives of the project are to: 1) explore and implement innovative ways to support senior citizens to access and use public services through personal mobile technologies that are based on open government data; 2) develop and deploy co-creation approaches and methodologies to engage senior citizens effectively; 3 ) develop a situated, practice-based understanding of accessibility, mobility and usability of services from a seniorcitizen point of view; and 4) develop a framework for impact assessment and evaluation for co-creation approaches to open service development for the aging population.

The project consists of four trial sites, each with their own focus: extending independent living, in South Lakeland (England) (our site); social inclusion, in Bremen (Germany); a safe and accessible city for elderly people, in Zaragoza (Spain); and personal health information, in the Region of Central Macedonia (Greece). These trial-sites and applications were designed to cover a broad range of usage scenarios, and during the co-creation process this led us to focus on apps that were not being covered at other sites. While not being especially unique it is also worth noting that the project also had to adhere to a series of contractual deadlines on a tight timeframe, and was subject to close scrutiny of the project's progress.

At Lancaster University, we had established relationships with Age UK prior to the grant writing, whose input shaped the South Lakeland project reported on here from the start and throughout. Age UK provides member-based (albeit free)

\footnotetext{
${ }^{1}$ We do not concern ourselves here with a debate about whether or not what we describe of our participant engagements is consistent with 'pure' co-creation (if there is such a thing $[5,9]$ ); nor do we belabor the subtle differences between co-creation and participatory design or co-design or anything else along that spectrum. For better or worse our approach did not adhere to a particular orientation amongst these related approaches.
} 


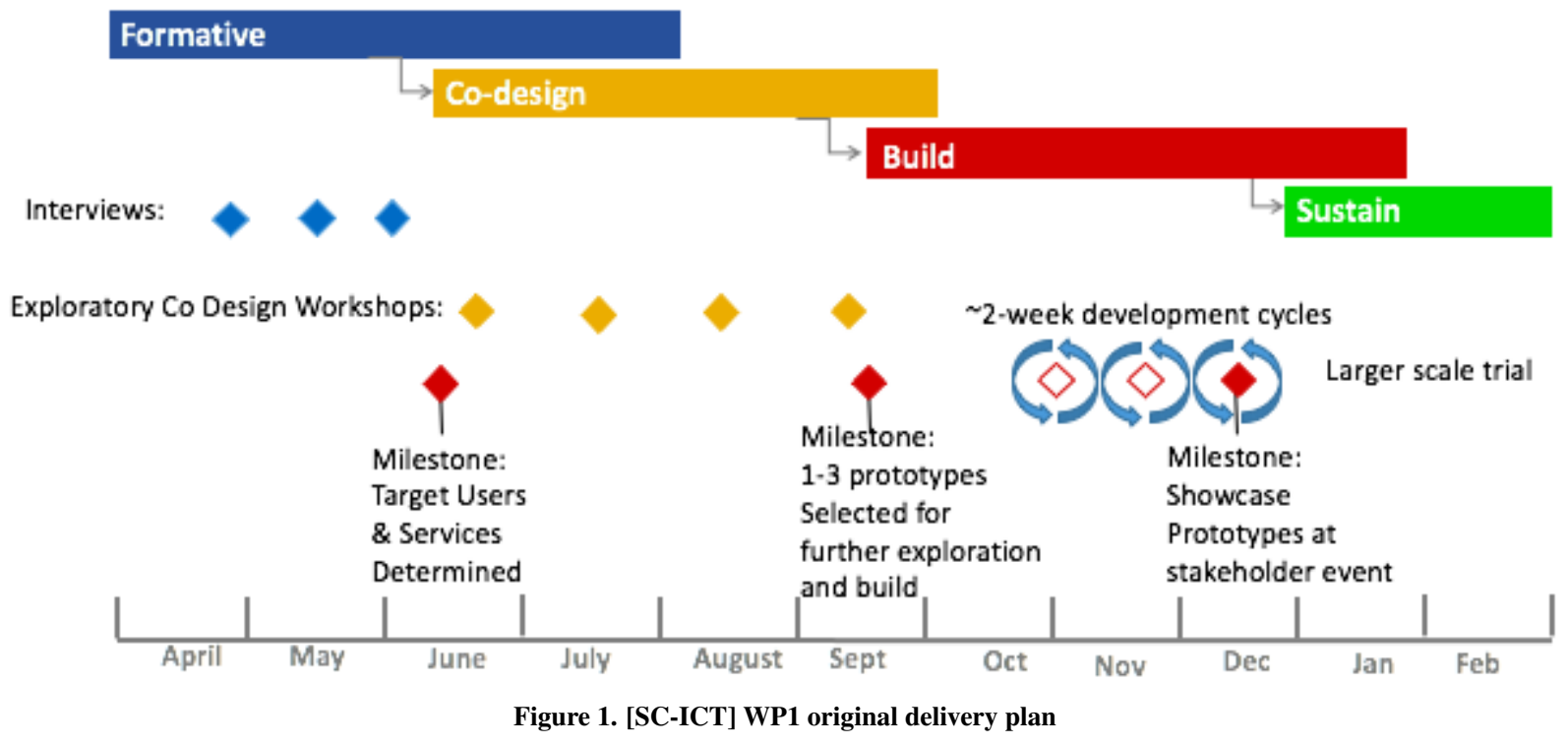

services for post-retirement adults, with an average member age of 74. The services they offer-a mix of practical help and social activities - are geared toward supporting independent living, informally described as "keeping people out of the doctor's office, in their homes, and happy." They also conduct evaluations of members' needs to determine whether they require any additional assistance, and liaise with government services when needs are identified. Age UK specifically, and repeatedly, asked that we focus on the problem of loneliness. As they explained, not only is loneliness a common complaint for their members, but it can greatly contribute to ill health; hence they believe that addressing loneliness would help foster both mental and physical well-being, keeping people living independently longer.

These commitments inherently steer the co-creation process, as we seek to ensure our stated objectives are met and our partners are happy. While we will explore this theme further later, we note for now that the a priori agenda emerging from these commitments is potentially at odds with a pure 'inductive co-creation approach' (our own terminology) that seeks to incrementally construct an understanding of the design space from the 'bottom-up' rather than 'top-down'-both by encouraging us to defer uncritically to the framings advocated by our stakeholders, and by preemptively constraining the solution space through initial scoping prior to engaging participants.

\section{Research Activities}

We based our activities on a technology-mediated innovation co-creation framework [19]. This is based on a traditional "plan, act, reflect" action research process [25] across an overlapping four phase process (formative, co-design, build, and sustain) and paced by project milestones.

In the Formative phase, a series of interviews were held with older adults to gain an initial understanding of their experiences of daily living, and with representatives of both Age UK and the South Lakeland District Council to understand some of the challenges older adults experience with regards to independent living. With such an enormous scope at the outset, a significant portion of time was spent early on in the project trying to narrow this scope down from independent living to specific examples of mobile apps that could be co-created. Simultaneously we worked to build up a participant pool and formed a core user group who were committed to engage with regular activities. Initial workshops were then held that focused the work onto a number of key themes. In the Co-Design phase workshops, themes were further explored, along with technologies that would improve experience in these themes. This took the form of ideating new interfaces and ways of interacting with technology, and re-purposing interfaces from other domains. During the Build phase, the researchers began to build prototypes that would embody emerging designs. They allowed the user group to gain a sense of how systems would operate and sought feedback during development. The workshop we describe in detail in this paper took place at the point of overlap between the Co-Design and Build phases, where the two activities are conducted iteratively. Subsequent Build activity produced final applications for deployment, and in the Sustain phase (underway at the time of writing) researchers are working with the project partners to deliver these technologies.

\section{Recruitment}

In partnering with Age UK, we focused on a subject population of interest to them, i.e. individuals over the age of 55 for whom loneliness is a known risk factor. This did not mean, however, that we focused our recruitment on individuals assessed as being extremely lonely, as Age UK explained they were interested in both mitigating and preventing loneliness.

One of the practical benefits of partnering with Age UK at a very early stage was that they were able to help with recruitment of participants, granting us special access to their events to meet older adults in the area (cf. [45]). These events included knitting groups, exercise classes, lunches, and special events (e.g. senior Olympics), where we spoke with attendees about the project, about their experiences with technology, and 
about what needs we might address in designing technologies specifically for them. It was more difficult than anticipated to recruit from these groups: as these events were not geared specifically around technology, and people came to them for a number of reasons unrelated to participating in research, many individuals politely declined to speak with us. The individuals who were enthusiastic about speaking with us about technology, however, were invited to join us at forthcoming workshops. Leveraging our connection with Age UK in this way naturally excluded some potential subjects of interest, such as harder to reach (i.e. socially isolated) individuals. In hindsight, it also naturally favored recruitment of those less likely to currently be experiencing loneliness, as they were able to attend these Age UK events.

\section{Application Concept Development}

Technological outputs from our South Lakeland group within the Mobile Age project include a suite of apps and services. The application discussed in this paper is the Events app, which aims to reduce barriers for older adults in finding and attending social events, thereby reducing loneliness. The application concept and design were co-created with the participants in earlier workshops [10]:

W1, T=0: Introductions. Participants were asked to describe personal experiences of use of mobile and web technologies.

W2, $\mathbf{T}=+3$ days: Lived Experience. We explored participants' typical week with a paper-based calendar filling exercise, asking for information about what they currently do (e.g. personal, eating, social, fun), how they decide what to do, and how they attend the activity.

W3, T=+1 week: Theme Identification. Through discussion, we identified various themes emerging from the prior workshops. Transport was identified as a key issue facing our older adults (driving at night, public transport availability in rural areas, time it takes to get to a doctors or hospital appointment). Trust in data and services was also a clear theme. To reduce the number of services in which our target users would need to forge trust, we began to think about creating a 'trusted portal' where older adults might access various pages and apps, e.g. an Events app and a Services app.

W4, T=+3 weeks: Theme Prioritization. We invited participants to help us prioritize themes through a card exercise. The themes taken forward were 'Planning' and 'Social Interaction', in part due to their convergence with Age UK's priority of reducing loneliness.

Co-design of the Events app began at workshop 5 and continued in several subsequent workshops, interwoven with codesign of the Services app:

W5, T=+12 weeks: Events A. We discussed challenges of accessing and attending events, helping to inform where event data could come from and what might be of interest to our participants. We also began discussion of their experience of using websites.
W6, T=+14 weeks: Events B. Based on W5, we asked participants to describe their experience of using three popular websites, focusing on what they found useful, interesting or annoying. From this we identified a key design principle to guide our design: striving for a balance between customizability and users' cognitive load.

W7, T=+15 weeks: Services A. We discussed various services and the notion of accessing them through mobile tech. This was motivated by our remit to look at independent living and (open) government data/services.

W8, T=+17 weeks: Services B. We did a demo of the first high-level Services prototype and got feedback on the design. From this we decided to build a simple Services discovery page in the portal which lists services sourced from the Age UK South Lakeland website.

W9, T=+21 weeks: Prototype Feedback A. We did a demo of the portal with the Events app and got feedback on the design, navigation, and missing features. We further explored services which could feasibly be added to the app.

W10, $\mathbf{T}=+37$ weeks: Prototype Feedback $B$. We got more feedback on the Events app, and explored requirements of the Services app.

W11, T=+40 weeks: Events $C$. We conducted further discussions regarding the Events app, back-end technologies and limitations, search capabilities and limitations, and the impact of app failures on trust.

W12, $\mathbf{T}=+42$ weeks: Services $\mathrm{C}$. We discussed access to and use of services by older adults (participants and their peers) relevant to the app and the project's remit, e.g. church newsletter and befriending services.

W13, $\mathbf{T}=\mathbf{+ 5 2}$ weeks: Services $\mathbf{D}$. We conducted a South Lakeland Housing workshop with a separate group of older adults, demoing the apps and discussing whether they were relevant to them and/or how to make them more relevant.

W14, T=+56 weeks: App Promotion. See the App Promotion Workshop subsection.

The resulting Events app is intended to not only raise awareness of events, but, most significantly, to present information tailored to the individual's ability to get to an event. Combining mobile sensor data, some limited personal information, weather forecasts, and open public transport and traffic data, the app filters events based on factors such as distance to the user, whether the event is public transport accessible, and whether the event's finish time would lead to part or all of the journey taking place in the dark-an important consideration for older adults for whom some age-related factors affect confidence and driving ability at night. The app is also configurable to users' maximum walking time or distance to accommodate older adults with limited mobility, e.g. recommending events that are public transport accessible, but ensuring the walking time between bus stops does not exceed five minutes.

This app is accessible through the Mobile Age application's trusted portal: a secure front-page within the app providing 
shared functionality between Mobile Age apps, and where users can access other provided services. Subsequent cocreation activities, with different groups of participants, contributed the other apps and services within the Mobile Age application suite. As the focus of this paper is on the interdependencies and constraints that shaped the co-creation of the Events app and how these contributed to mismatches in expectations between participant-users and researcher-developers, we reserve discussion of the final applications resulting from this project for future publications.

\section{APP PROMOTION WORKSHOP}

The App Promotion workshop, the most recent workshop (at the time of writing), is the source for all participant quotes cited herein. By way of reminder, the aim of the workshop was to better understand how we might ensure significant uptake of the app throughout the target older adult community, with a particular emphasis on what role our participants might play in championing the app among their peers. The session was planned to cover four topics as described below. While we had planned to progress sequentially through each of these topics, we did not restrict participants from talking about these topics out of turn as part of the natural flow of conversation.

What do you think you're getting? We began the App Promotion workshop by asking participants to write on an index card a description of the app they thought was being developed. After completing their cards, participants fed back to the group; after which point the lead developer on the project described the app that he was building. The aim of this brief exercise was two-fold: 1) to see whether participants were in agreement with each other and with the project team regarding the tool they would be receiving; and 2) to ensure that we had a shared understanding of the app before proceeding with discussion around how to effectively disseminate such a tool.

Who is the app for? We asked participants to tell us who would benefit from the app as a way of a) determining the breadth of appeal among older adults (and hence the scale of our dissemination), and b) identifying individuals or groups of strategic interest for promoting the app.

How should we get the word out? Our main interest in planning this workshop was to elicit insights from participants about how to reach our target audience. To this end, we asked participants how they and their peers come to know about new things (e.g. where do they find information?, who tells them about these things?).

How do we overcome resistance? As part of answering the previous question, we asked participants to consider how they and their peers might a) come to know about new apps, and b) become interested in our app, specifically. The primary focus of this discussion was attitudes that might negatively affect adoption of apps (e.g. how do they come to trust new things?, how might we spark curiosity in the app?), though physical, cognitive and practical barriers to adoption were also discussed.

There were 7 participants who consistently attended workshops during the Co-Design stage (12 in total), 6 of whom attended this App Promotion workshop- 4 females, 2 males.
This was a self-selecting group, who attended the workshops out of interest and arguably for social reasons, rather than for any form of enticement. The mean age of participants was 68.5 years old; all participants live in South Lakeland UK, a fairly rural location (though all have Internet access); three are married (P3 and $\mathrm{P} 4$ are married to each other), and three are widows/widowers. We would describe two of our participants as expert technology users, and only two as greatly lacking in confidence, though there were no true novices in our group. We note that while a seemingly small number of participants for a study, this is in keeping with similar studies, and aligns with Lindsay et al.'s [31] recommended older adult participatory design group size of $4-5$ (over-recruiting by $20 \%$ in case of dropouts).

\section{Workshop Analysis}

The participants at the App Promotion workshop all actively contributed to the co-creation of the app under development through their attendance at prior workshops. In addition to the two workshops specifically dedicated to demoing the app, participants were also shown ongoing development in a number of workshops, so will have seen the app at least six times prior to the App Promotion workshop. Below we present the findings from this fourteenth workshop, organized according to our pre-planned questions for the sake of readability (note that the discussion did not unfold neatly into these four distinct topics).

\section{Participants' understanding of the app}

Having explored both 'events' and 'services' in prior workshops (5-6 and 7-8, respectively), participants were confused as to whether they were getting several different apps or a single all-singing-all-dancing one (see Table 1). ${ }^{2}$ For example, while P1 indicates in her description of the app that it will help her find events, she then suggests that it will also help her get council advice, sort transportation to the hospital, and find local tradesmen. Similarly, in addition to being a local events finder, P6 expects the app to provide her easier access to government, local council, non-governmental, and health services. P2 is the only participant who did not mention events in her description of the app, which fits with her stated preference for a services app:

P2: "See I would find the services side more useful than the events side, because as far as events go, there are specific things we're interested in... So sometimes I may want to search for an exercise class or something. But apart from that, it's services."

Participants were in agreement that a service finder would be more useful to them than an events finder, but some focused on services in the sense of local tradesmen (P1, P2, P5), whereas others focused on services in the sense of transportation (e.g. getting to the hospital: P3, P4). The former

\footnotetext{
${ }^{2}$ Note that we have plans to develop at least one additional app that more directly attends to the project's focus on older adults' access to government services. We view both the Events app and Service app(s) as promoting independence: the former by attending to older adult loneliness which is linked with declining mental and physical health; the latter by attending to the need to effectively conduct activities of daily living in a digital world.
} 
of these surfaced doubts about the uniqueness of the app ("I mean there are things like Which? services, aren't there? Which? magazine has local services" [P5]; "See something like that I'd use South Lakeland Sell And Seek; seeking a builder, seeking an electrician, you know" [P1]]); and the latter of these surfaced inherent limitations in the app merely pointing to existing services ("There isn't an answer, is there? Well, say you want to get to Liverpool at half past four in the morning, and you were on your own...It's the fault of the service that there isn't a service. [The app would be] looking for something that isn't there" [P4]).

Another apparent source of confusion is participants' interpretation of accessibility, and its importance, within the context of the app. For example, P3 insists that the app would function as a simplified portal onto the Internet that hides problematic features of standard interfaces (e.g. keyboards): "You've got to get rid of all the things you don't need, and make it very simple." But as P5 notes to his disappointment, if the goal is making events accessible, then accessibility for the true novice limits the value of the app for the more tech literate older adults: e.g. removing features like the keyboard may limit the user's ability to specify details that could otherwise be useful in returning events of interest. Disagreement about the target users' technological skills (see next section) contributed to differences of opinion about how relevant simplicity was to the app. In P6's view, the app should be designed first and foremost for older adults who would not be able to access services via any other technology: "You're not teaching people how to use the Internet. You're using it as a vehicle to let them access local services, local things like health... You're giving people the opportunity through your app." This contrasts with the view, held by P1 and P2, that those with no technological skills will have no interest in the app, and therefore the interface can be designed for use by individuals with a basic mobile phone/app skill set.

Some more minor discrepancies in expectations include: a) the fact that the app will not be usable beyond South Lakeland (contrary to the hopes of P1 and P4), and b) that users will not be able to purchase tickets to events through the app (contrary to the hopes of P3 and P5).

\section{Who is the app for?}

Although all participants clearly understood that Mobile Age is interested in designing technologies for older adults, the banding of 'older' as age 55+ adopted from our partner, Age UK, presented complications in identifying intended users for the app. Most notably, having described the app as being, "Specifically designed to [be] aimed at older internet users rather than more expert younger people" (see Table 1), P2 then argued we would find greater uptake among younger people - specifically, those at the younger end of 'older adults', i.e. closer to 55 than 80 , "because 55 is quite young these days." This reveals P2's assumption that the older a person is the less technologically literate they are likely to be (cf. [24]):

P1: "I think [the app is] going to be of most use for people that are really computer literate now. And we're all just dabbling in it, I think, compared with the younger people."
Table 1. Participant responses to 'What do you think you're getting?'

\begin{tabular}{|l|l|}
\hline P1 & $\begin{array}{l}\text { To stop isolation, being able to find things to do. Give } \\
\text { information about events in my area or any other area } \\
\text { I may visit in this country (abroad?). Helping with } \\
\text { problems re hospital visits and council advice. Finding } \\
\text { local tradesmen. }\end{array}$ \\
\hline P2 & $\begin{array}{l}\text { An AP [sic] that will help older people become aware } \\
\text { of services that might interest them. Also to help them } \\
\text { access these services, either via websites, transport to } \\
\text { events, etc. Specially designed to aimed at older internet } \\
\text { users rather than more expert younger people. }\end{array}$ \\
\hline P3 & $\begin{array}{l}\text { An app to enable older people to discover what } \\
\text { events/services relevant to them are taking place in their } \\
\text { locality. Info to include date, time, place, who, what, } \\
\text { price, level, etc. Needs to be simple to draw people in } \\
\text { and use it. At the moment there are limited websites for } \\
\text { services. }\end{array}$ \\
\hline P4 & $\begin{array}{l}\text { Easily accessible information in one place. Hopefully } \\
\text { up to date info. Will be available wherever you are. }\end{array}$ \\
\hline P5 & $\begin{array}{l}\text { An app to allow people to find local events and informa- } \\
\text { tion about them as well as how to get there. This will be } \\
\text { by use of a platform which is currently being developed. }\end{array}$ \\
\hline P6 & $\begin{array}{l}\text { An app that enables users (users = elderly) to access: } \\
\text { * local services (Government, Council) and contracts } \\
\text { routes * Access to local health services, Drs, Hosp. etc. } \\
\text { * To non-governmental services. }\end{array}$ \\
\hline
\end{tabular}

Technical hurdles aside, participants struggled to think of subcommunities within the larger community of 'older adults' who would benefit from the events app currently under development. For example, rather than searching for new events to attend, $\mathrm{P} 2$ is more likely to identify a club to attend on a regular basis, and she tends to hear about these already via low-tech means such as leaflets in the library. She wonders, therefore, if using an app to find events is "a bit of a young market."

Similarly, P5 struggled to imagine a scenario when he would use the app:

P5: “I'm going to several events in the next month, and I pick them up from posters, and um, from radio and things. So I don't think-I don't think I would necessarily look at your app to say, 'I've got to fill in this week here,' and 'What's on?"'

This is particularly problematic since, as P6 right noted, older adults would need to identify real value in an app if they were to make the required investment to access it:

P6: “... somebody's going to have to buy [an iPad, for example], and they're not going to buy that if they don't think it's going to be-if they think it's only just going to tell them what's on at the [local arts centre] on a Saturday night."

Eventually, a small number of sub-communities were identified as potential beneficiaries of this technology. P5 sug- 
gested that "you can get quite a lot of people suddenly requiring" a means of finding events among the recently bereaved, who are trying to establish a new social life. Following that logic, though not explicitly proposed by the participants, the events app might be similarly useful for recently disabled older adults - particularly given the features being developed to afford users information regarding the accessibility of these events. Participants also suggested that individuals in nursing homes might be a "captive audience" [P6] for the app, without clearly articulating a rationale of benefit for this community.

Conspicuously absent from this list of likely users of the app are both the truly socially isolated and individuals at the extreme of technological inability. It would make sense if socially isolated individuals were thought to be isolated for reasons that would make it hard for them to attend events in the first place, such as major mobility problems, though this rationale was not stated explicitly. Participants were vocal, however, regarding their opinion that the technologically inept were deemed incapable of using even the most user friendly app:

P2: "I've been using computers since I was in my, sort of, early 20s, I think. But there are lots of people like my husband who is 81 now, who is absolutely hopeless. He's just tried and tried and tried but [it] just can't sink inwon't sink in at all."

It is important to note, however, that participants' assessment of having failed to appeal to two ostensibly relevant groupsi.e. technologically less adept older adults and the socially isolated-is speculation, which may or may not be right. Critically, it highlights a limitation of our convenience sampling: that we may not have been close enough to key target users if we were asking our participants their opinions about what those other relevant users might think of the app.

\section{How should we get the word out?}

The participant workshops are held in a local community centre which acts as a focal point for many of the Age UK clubs and activities. Along the back wall are numerous pamphlets offering advice, providing information on available services, and promoting activities. It is common for participants to peruse these pamphlets during coffee breaks or after the sessions, taking with them ones of interest. While not originally part of our promotion strategy, it occurred to us that developing a pamphlet about our project or our application might be an effective strategy for promoting the app among a demographic familiar with and actively seeking out information in this format. Having asked participants, responses to this idea were as follows:

P1: “Everybody's got to have heard of Mobile Age before it even comes to that. To make people want-you know, to think, 'Oh, Mobile Age, I've heard of that.' ... So people are not suspicious of it. Because I would guess that if you say, 'Put this app on your phone,' a lot of people are going to be suspicious of that, even if they're used to using [apps]."

P2: “...You've got to do more than just say, 'There's this app.' You've got to say how - what you can load it on... [For example,] 'Have you got an iPad?', [etc.]...P5: "Even the word 'app' might frighten some people off."

P1: “...I wouldn't put anything on my phone that I've never heard of."

As a way of generating name recognition, participants argued for the importance of a media campaign with representatives of the project (not of Age UK) appearing on local radio or breakfast news programs (e.g. BBC Breakfast).

Participants were able to identify several routes for promotion of the app that had not previously been considered in the project. For example, while early on we had conceived of 'trusted intermediaries' (e.g. family, carers, outreach services) as potentially playing a role in enabling older adults to glean value from the apps we designed, we had not initially seen grandchildren as especially good in this role. ${ }^{3}$ As P2 noted, however, grandchildren will often suggest apps for their grandparents to put on their phones and tablets. P1 suggested that we deliver presentations to students in school, saying, "'Go and show your Granny or Granddad how you to do this or that,", or "maybe bring the grandparents in for a day, you know, 'Show your grandparents what you can do on your phone." P6 suggested we might target grandchildren-grandparents days that already exist in schools, her rationale being:

"I think if you just advertise it, people who are not tech savvy or are not interested in it or frightenened of it just won't come. I think it's got to come at them, sort of, sideways."

Another idea that was deemed especially promising for generating adoption was to leverage high traffic public displays, e.g. producing demo videos to be shown on televisions in doctors' waiting rooms "that showed the basics of that particular app" [P6]. P2 explained:

“... you're sat there... wanting to look at something, and a lot of things come round and round, and I've sat there and thought, 'Oh, that might be a good thing to do.' And I think they're an excellent source of information."

Also, identifying certain sub-groups who would benefit from the app revealed new partnerships that might be strategic for both recruiting participants and ultimately disseminating to users. These include partnering with bereavement groups [P5], with services that work with socially isolated individuals [P4], and/or with nursing homes ${ }^{4}$ [P5,P1]. For gaining uptake by residents of nursing homes, $\mathrm{P} 2$ suggested that we provide the app for wardens to use, "and then people could go in and see what information they could find, and then they may think, 'Oh well, that would be useful to have for myself.",

\footnotetext{
${ }^{3}$ Later this theme did arise in participant workshops, though we had still at the time of the App Promotion workshop not conceived of tangible ways to enfold them in our promotion strategy.

${ }^{4}$ To our credit, we had anticipated the latter of these and have established a relationship with a local nursing home, engaging with residents in co-creation workshops and planning deployment at the home.
} 
Most notably, however, and contrary to our expectations at the outset of this process, our participants did not feel confident in promoting the app to friends and peers. They expressed feeling ill-equipped to speak with authority on anything technical, which as they see it would include any mobile app no matter how simple the interface was. As P1 explained, "I could show my friends it, but if they started asking any questions, I'd panic! I wouldn't be able to- 'Oh yes it can do this,' 'Oh, but how does it do this?"' And even for participants who were more technologically confident at the outset, the co-creation process did not impart them with skills in communicating their knowledge to less knowledgeable peers - a critical failing in producing effective user champions for the app.

\section{How do we overcome resistance?}

The general approach for getting older adults to use the app suggested by participants is "to expose them to it in-on an occasion when they're not necessarily required to attempt to use it but could look at it in use by peers" [P6]. Another common theme is the need to dispel older adults assumptions that apps will entail various hidden costs and may contain viruses [P1]. Participants also suggested the app would need to be inviting to new users by including a demo of how the app works when it is first opened [P4].

But critically, when we asked participants if they had any ideas for overcoming resistance to apps among its potential beneficiaries, participants admitted that this was the most important and as yet unresolved issue at the heart of the project:

P6: "I think we're going right back to the beginning with that question, wasn't it, at our very first meeting where we were discussing how we were going to bring in the people who would benefit from it, and how we would make them curious enough to want to try to use it. And I think that's still a really major issue... [W]e've still got to get over the initial hump which is, if they haven't tried it already, through one means or another, how are you going to make them [try apps].

P3: "[H]ow do you draw them in? I've listened to all this and the problem still seems to be, how do we get people involved? I don't think we've sorted it."

\section{DISCUSSION}

\section{Expectations mismatch}

It was by no means inevitable that our stated focus on 'independent living' should result in an Events app. Through an extended scoping phase within our co-creation process, we chose only one of several strategies for addressing this challenge — namely seeking to mitigate loneliness, which tends to precipitate both mental and physical decline. And on its own, an Events app clearly does not solve all of the problems for older adults requiring assistance as they age. In some sense, therefore, it is not unreasonable that participants were surprised to have arrived at an Events app from the starting point of independent living. It may be that a mismatch between expected and actual technological outputs arose from having involved participants in scoping down to a very focused application that addresses only one part of the larger problem that had framed initial conversations.
Conversely, the advantage of having started so broad is that the application itself was not constrained, which meant we had a great deal of freedom to co-create. Despite how long it took to narrow down the project's focus, developing an Events app reflects the the fact that we undertook inductive research and did not apply our existing conceptions of applications within this domain. 5 But given that participants were not entirely on the same page as the development team, there would appear to be a breakdown of communication. It is worth noting that the composition of the research team also changed at numerous points throughout the project, so in addition to having to transfer expectations from the researchers to the participants we also faced the challenge of transferring expectations within the research team. We did not measure any potential drift in expectations of the project over time within the team, but it is likely that the framing of the initial co-creation workshop differed in significant ways to that of later workshops by virtue of being conducted by different people. Based on our experience we can but speculate on how brittle co-creation is in the face of changing research teams.

Additionally, our analysis points to a need for effective communication with participants about the decision making happening outside of the co-creation engagements. For example, some good ideas offered by participants did not align with the project objective around open government data-which is to be expected, as our workshops did not especially emphasize this research focus. And in fact, the Events app idea did not come directly from the mouths of participants; rather, we saw the Events app as bridging the interests of many of the different parties involved. Not including participants in some of the behind-the-scenes conversations about those competing interests meant they retained expectations about the app that were no longer (or never really) in development.

Some of the participants' demonstrable confusion about the app might have been attenuated through greater expectation management, but clearly scoping decisions made prior to user involvement shaped the eventual co-creation outputs [31, 39], contributing to mismatch between what participants thought they were getting and what we though we were developing for them. We learned from this experience the importance of conducting preliminary co-creation with potential end-users in parallel to, rather than after, co-creation with organizational stakeholders. As Wright \& McCarthy note [46], it is difficult to know who the 'right users' are in advance; and deciding potential participants at an early stage can reduce diversity of viewpoints that might strengthen the co-creation outputs [39]. Given the challenges of recruiting older adults [17] it seemed expedient at the time to leverage our existing partnership with Age UK to ease this burden. The unexpected tradeoff, however, was adopting their banding for 'older adults' as being 55+- an especially broad range that includes individuals at different stages of life and from different generations. Consequently for us there was little uniting our participants in terms of shared problems around which to orient co-creation (see [31]),

\footnotetext{
${ }^{5}$ Clearly this is a double edged sword: If we had known from the start that we wanted to build an Events app we would have designed a rather different series of co-creation workshops and most likely would not have found expectation mismatch to quite the same extent.
} 
as older adults are even more diverse in terms of abilities, lifestyles, health and income than younger adult populations $[16,31]$. If instead we had approached older adults prior to the grant writing stage, we might have had insights that led to us forging less obvious but more strategic partnerships, opening doors to not only the right participants but also to high impact routes for disseminating the application. Indeed, knowing what these partnerships and pathways to impact are would have enabled more effective budget planning to allow us to capitalize on some of the more inspired ideas for promoting the application, such as hosting events with grandchildren and their grandparents, developing pamphlets, advertising on public displays, and engaging with media. ${ }^{6}$

\section{A Priori Constraints}

We were surprised to discover that having actively co-designed an app does not mean participants think it is a good idea. Surely one of the benefits of engaging with participants in this way is that it assures buy-in from the participants themselves, at a minimum; so how did we get so far down the line towards designing a system that participants were not sure they wanted?

Ironically, a principal failing of ours may have been the instrumentalization of co-creation as a process for overcoming resistance to adoption of products [35], which served to narrow discussion to the realm of technological solutions. End-users in general are typically poorly equipped to articulate the most suitable technological solutions to their problems because they lack the technical knowledge needed to understand the scope of possibilities-perhaps even more so for older adults whose technical knowledge is even more limited in many cases. They (all end-users) typically ask for solutions that are quite similar to things they have seen before-e.g. a new kind of Facebook, a new kind of calendar, a mobile phone with a slightly altered interface. It is not necessarily appropriate, therefore, to expect participants to act as capable partners in design [45]. Co-design ought not be conceived, then, as a process whereby participants actively design technologies; rather, it has been shown to be more successful when co-design is approached as an activity of "mutual learning," whereby both parties learn from each others' expertise [33] (see also [36]). This suggests the failing here was two-fold: the co-design process may have yielded more appropriate outputs if we had 1) conducted more expansive and generative participant engagements, i.e. less solution oriented [28, 30, 41]; and 2) located the onus of designing the apps exclusively with the research team, and viewed our co-creation obligation as communicating our design thinking to the participants.

Clearly our desire to produce an application that pleased our project partners and funders further contributed to having conceived of an app for which there were no eager customers-at least in the opinion of our participants. Aiming to please all parties caused us to overly focus on nuggets from participants'

\footnotetext{
${ }^{6}$ We note that this is in line with the Research Council UK's stated rationale for requiring grant applications to include a Pathways to Impact (http://www.rcuk.ac.uk/innovation/impacts/), and with their frequent specification that proposals must be demonstrably co-created.
}

dialogues which matched our project partners' aims and expectations, in this way managing our participants as "the unruly other" [38] that needed to conform to our a priori agenda. The formalized project objectives had an impact on which ideas arising during the workshops we were able to entertain, as candidly reported by Lindsay et al. [31] in their project: "We have frequently encountered older people keen to tell us that the ideas that we are proposing are 'rubbish' or 'unnecessary' but the rigid structure of the funding agreements have meant that this advice cannot easily be acted upon." In our case, the project was motivated by a real need to ensure that older adults benefit from rapid advancements in mobile technology; but we were trying to accomplish that within the context of a group of end-users who had some degree of inbuilt resistance to mobile technology from the outset. Had we engaged sufficiently with older adults in advance of our co-design workshops, we may have been better prepared to address our participants' concerns and reservations about apps. Instead, it could be argued that much of the energy on this project was devoted to convincing participants that their lives would be enhanced by apps (see $[27,44])$.

\section{User champions and trust}

We had also assumed that the co-creation process would produce de facto 'user champions' of our participants - that their inside knowledge and enthusiasm for what was in part their idea would make them natural advocates committed to spreading the word to their peers and neighbors. Instead what we found was that our participants did not feel capable of promoting something as technical as an app. Whereas it is possible that young adults (say in their 20s) would feel quite comfortable talking about and promoting an app they had helped design, older adults are characteristically (if not universally) lacking in technological confidence [27, 26], and it was a critical oversight that our co-design workshops were not designed to impart this confidence to them. In hindsight, making user champions of our older adult participants would require significant provision for user training, not only to offset their anxiety around new technologies but also to compensate for age related declines in fluid intelligence that affect their ability to learn new technologies [15, 23].

Older adults' attitudes to technology (again, to generalize) also affected the perceived trustworthiness of the application in ways we had not anticipated. Specifically, this demographic has been shown to approach new technologies with skepticism and caution [27, 26], and while we had assumed that codesigning with individuals from our target user group would naturally imbue the app with a special status from having been endorsed by one's peers, clearly our application was not inferred the status of 'trustworthy' by virtue of having been codesigned with older adults (see discussion around producing a pamphlet). Further, it was particularly interesting to discover that despite partnering with Age UK, a trusted organization among our prospective users, that trust did not necessarily transfer to Mobile Age by association. Participants suggested instead that they and their peers would need to form a trusting relationship with us, the project team, directly (e.g. through media promotion) to feel comfortable downloading an app. 
Perhaps the greatest challenge in making user champions of older adult co-creation participants is their sense of responsibility as protectors (of themselves and other older adults) against the encroachment of digital technologies [27, 26]. Older adults describe feeling pressured to adopt digital technologies, stressed about having to learn to use them, and worried about their friends and peers who may not be able to keep up with technological change (ibid). It is arguably uniquely unnatural for older adult participants to become technology advocates, when in other contexts they strive to protect themselves and others from encroachment of technologies that make them feel old and incapable (see "situated elderliness" [8]).

\section{CONCLUSION}

At the time of the workshop described in this paper we had sought extensive user input and begun the development of our Events app. Our rationale for conducting a workshop around the theme of dissemination was to draw out specific details about how to reach likely users and maximize uptake; we had not anticipated this workshop to be so revealing of flaws in our assumptions about co-creation and the challenges of this methodology. A critical commentary of our progress at that point would suggest that we and our co-designers had together designed an app that neither solved the problem we set out to address with our research project nor appealed to our target users, including, incredibly, our own workshop participants.

Our initial analysis identified some of the reasons we believe we ended up in this situation. In large part, we point to the ways in which early scoping with project partners built momentum in a particular direction, and it was a long time before co-creation workshops revealed that direction to be flawed. Further, having brought various stakeholders in to co-create the grant, we deferred unquestioningly to framings advocated by these stakeholders and as such failed to critically engage with terms such as "loneliness" and "independent living." Another factor was committing to design for a target customer who was too broadly defined (i.e. the "older adult," as categorized by our partners as anyone 55-years-old or older), not fully examining our end users' many relevant traits and how they influence their decision making. Not having completed this step, we recruited participants who did not necessarily match the profile of our target user, so we were ultimately cocreating with the wrong individuals. In particular, we failed to account for the technological skill set of many older adults and their attitudes toward mobile technology which affect their likeliness to adopt and willingness to act as user champions.

Reflecting more deeply we observe that the App Promotion workshop (quite by accident) replicated some of the essential elements of lean customer development [1]. In particular, the questions we posed for our participants forced them to articulate the problem the app was aiming to solve (What do you think you're getting?), begin to create a target customer profile (Who is the app for?), and examine the assumptions underpinning their design concept (How should we get the word out? and How do we overcome resistance?), thereby enabling them to see the flaws in the app they had helped conceptualize. Lean customer development espouses the importance of getting out of the office and engaging with customers. What became clear is that while we had actively striven to do this through our co-design process the use of a small cohort of participants throughout had essentially just created another 'office' (albeit in a different physical location) in which ideas were allowed to develop without the needed levels of scrutiny and challenge.

Furthermore, this workshop enabled us to examine our own assumptions about the outcomes of a co-creation methodology. Most importantly we discovered that co-creating the grant proposal with stakeholders does not guarantee a smooth path through co-designing with participants. Firstly, we found that co-creating our proposal created a set of stakeholder and researcher-developer expectations that impacted on the codesign in ways that were not clear to participants (or indeed us until much later). And secondly, as is already known, co-creation inevitably involves a great deal of flexibility and change; but being able to make necessary changes may happen further downstream than may be accounted for and easily accommodated in project timelines. In our case, it was fourteen workshops and a full year into the co-design stage before we elicited key insights into the implications of our scoping. While the App Promotion workshop was not intended as such, it proved an important pivot point for the project, as we have shown. Clearly this particular App Promotion workshop could not have been held much earlier, as the questions we asked required that participants go through the process of developing their own understanding of the problem and the potential solution space, and have an app to think about promoting. And yet co-creation seems to benefit from providing opportunities for pivoting to happen early and often, ideally during the grant writing stage and thereafter. Given that such pre-work itself requires funding, how might this scoping phase be accommodated within funding structures?

We end this paper without having described the final suite of applications developed for this project. In reporting on the development and evaluation of a solution, by necessity (i.e. page limits, clarity) researchers must omit much of the messiness that occurs in earlier stages of the work-the missteps, the erroneous assumptions, the teachable moments that advanced a researchers' own understanding of best practice. Believing a degree of messiness to be endemic to co-creation, we set out to make this messiness the subject of the paper in order to illustrate by example some of the principles already espoused in co-creation literature, and therefore to demonstrate the need to seriously attend to these prior works when considering engaging participants. In addition, we have organized our telling of this experience around explicating certain interdependencies and constraints that prevented us from engaging in a more inductive co-creation approach, to highlight the need for researchers to devise means of insulating the process from the dynamics we describe.

\section{ACKNOWLEDGMENTS}

This project has received funding from the European Union's Horizon 2020 research and innovation programme under grant agreement No 693319. 


\section{REFERENCES}

[1] Cindy Alvarez. 2017. Lean customer development: Building products your customers will buy. O'Reilly Media, Inc.

[2] Ellen Balka. 2010. Broadening discussion about participatory design. Scandinavian Journal of Information Systems 22, 1 (2010), 77-84.

[3] Julia Barrett and Stuart Kirk. 2000. Running focus groups with elderly and disabled elderly participants. Applied ergonomics 31, 6 (2000), 621-629.

[4] Maria Beimborn, Selma Kadi, Nina Köberer, Mara Mühleck, and Mone Spindler. 2016. Focusing on the Human: Interdisciplinary Reflections on Ageing and Technology. In Ageing and Technology: Perspectives from the Social Sciences, Emma Domínguez-Rué and Linda Nierling (Eds.). Transcript Verlag.

[5] Jeanette L Blomberg and Austin Henderson. 1990. Reflections on participatory design: lessons from the Trillium experience. In Proceedings of the SIGCHI conference on Human Factors in Computing Systems. ACM, 353-360.

[6] Claus Bossen, Christian Dindler, and Ole Sejer Iversen. 2012. Impediments to user gains: experiences from a critical participatory design project. In Proceedings of the 12th Participatory Design Conference: Research Papers-Volume 1. ACM, 31-40.

[7] Claus Bossen, Christian Dindler, and Ole Sejer Iversen. 2016. Evaluation in participatory design: a literature survey. In Proceedings of the 14th Participatory Design Conference: Full papers-Volume 1. ACM, 151-160.

[8] Eva Brandt, Thomas Binder, Lone Malmborg, and Tomas Sokoler. 2010. Communities of everyday practice and situated elderliness as an approach to co-design for senior interaction. In Proceedings of the 22nd Conference of the Computer-Human Interaction Special Interest Group of Australia on Computer-Human Interaction. ACM, 400-403.

[9] Tone Bratteteig and Ina Wagner. 2016. Unpacking the notion of participation in Participatory Design. Computer Supported Cooperative Work (CSCW) 25, 6 (2016), 425-475.

[10] Christopher N. Bull, Will Simm, Bran Knowles, Oliver Bates, Nigel Davies, Anindita Banerjee, Lucas Introna, and Niall Hayes. 2017. Mobile Age: Open Data Mobile Apps to Support Independent Living. In Proceedings of the 2017 CHI Conference Extended Abstracts on Human Factors in Computing Systems (CHI EA '17). ACM, New York, NY, USA, 2410-2415.

[11] John M Carroll, George Chin, Mary Beth Rosson, and Dennis C Neale. 2000. The development of cooperation: Five years of participatory design in the virtual school. In Proceedings of the $3 r d$ conference on Designing interactive systems: processes, practices, methods, and techniques. ACM, 239-251.
[12] Luigina Ciolfi, Gabriela Avram, Laura Maye, Nick Dulake, Mark T Marshall, Dick van Dijk, and Fiona McDermott. 2016. Articulating co-design in museums: Reflections on two participatory processes. In Proceedings of the 19th ACM Conference on Computer-Supported Cooperative Work \& Social Computing. ACM, 13-25.

[13] Andrew Clement and Peter Van den Besselaar. 1993. A retrospective look at PD projects. Commun. ACM 36, 6 (1993), 29-37.

[14] European Commission. 2018. What you need to know about Horizon 2020 calls. http://tinyurl.com/nvhex7x. (2018).

[15] Sara J Czaja, C.C. Lee, Andrew Sears, and Julie A Jacko. 2007. Information technology and older adults. In Human-Computer Interaction Handbook: Fundamentals, Evolving Technologies and Emerging Applications (2nd ed.). Erlbaum, Mahwah, NJ, Chapter Information technology and older adults, 777-792.

[16] Sara J Czaja and Chin Chin Lee. 2007. The impact of aging on access to technology. Universal Access in the Information Society 5, 4 (2007), 341.

[17] Marianne Dee and Vicki L Hanson. 2014. A large user pool for accessibility research with representative users. In Proceedings of the 16th international ACM SIGACCESS conference on Computers \& accessibility. ACM, 35-42.

[18] Rex Degnegaard. 2014. Co-creation, prevailing streams and a future design trajectory. CoDesign 10, 2 (2014), 96-111.

[19] Maria Angela Ferrario, Will Simm, Peter Newman, Stephen Forshaw, and Jon Whittle. 2014. Software engineering for 'social good': integrating action research, participatory design, and agile development. In Companion Proceedings of the 36th International Conference on Software Engineering. ACM, 520-523.

[20] Victoria Gerrard and Ricardo Sosa. 2014. Examining participation. In Proceedings of the 13th Participatory Design Conference: Research Papers-Volume 1. ACM, 111-120.

[21] Lorna Gibson, Paula Forbes, and Vicki Hanson. 2010. What can the' ash cloud'tell us about older adults' technology adoption. In Proceedings of the 12th international ACM SIGACCESS conference on Computers and accessibility. ACM, 301-302.

[22] Vicki L Hanson. 2009. Age and web access: the next generation. In Proceedings of the 2009 International Cross-Disciplinary Conference on Web Accessibililty (W4A). ACM, 7-15.

[23] Vicki L Hanson. 2010. Influencing technology adoption by older adults. Interacting with Computers 22, 6 (2010), 502-509. 
[24] Eszter Hargittai and Kerry Dobransky. 2017. Old dogs, new clicks: Digital inequality in skills and uses among older adults. Canadian Journal of Communication 42, 2 (2017).

[25] Gillian R Hayes. 2011. The relationship of action research to human-computer interaction. ACM Transactions on Computer-Human Interaction (TOCHI) 18, 3 (2011), 15.

[26] Bran Knowles and Vicki L Hanson. 2018a. Older Adults' Deployment of 'Distrust'. ACM Transactions on Computer-Human Interaction (TOCHI) 25, 4 (2018), 21.

[27] Bran Knowles and Vicki L Hanson. 2018b. The Wisdom of Older Technology (Non-) Users. Commun. ACM 61, 3 (2018), 72-77.

[28] Tuck Wah Leong and Toni Robertson. 2016. Voicing values: laying foundations for ageing people to participate in design. In Proceedings of the 14th Participatory Design Conference: Full papers-Volume 1. ACM, 31-40.

[29] Ann Light and Yoko Akama. 2012. The human touch: participatory practice and the role of facilitation in designing with communities. In Proceedings of the 12th Participatory Design Conference: Research Papers-Volume 1. ACM, 61-70.

[30] Ann Light, Tuck W Leong, and Toni Robertson. 2015. Ageing well with CSCW. In ECSCW 2015: Proceedings of the 14th European Conference on Computer Supported Cooperative Work, 19-23 September 2015, Oslo, Norway. Springer, 295-304.

[31] Stephen Lindsay, Daniel Jackson, Guy Schofield, and Patrick Olivier. 2012. Engaging older people using participatory design. In Proceedings of the SIGCHI conference on human factors in computing systems. ACM, 1199-1208.

[32] Michael J Muller and A. Druin. 2010. Handbook of HCI. Erlbaum, Mahway, Chapter Participatory design: The third Space in HCI, 1050-1075.

[33] Toni Robertson, Tuck W Leong, Jeannette Durick, and Treffyn Koreshoff. 2014. Mutual learning as a resource for research design. In Proceedings of the 13th Participatory Design Conference: Short Papers, Industry Cases, Workshop Descriptions, Doctoral Consortium papers, and Keynote abstracts-Volume 2. ACM, 25-28.

[34] Yvonne Rogers, Jeni Paay, Margot Brereton, Kate L Vaisutis, Gary Marsden, and Frank Vetere. 2014. Never too old: engaging retired people inventing the future with MaKey MaKey. In Proceedings of the SIGCHI Conference on Human Factors in Computing Systems. ACM, 3913-3922.

[35] Elizabeth B-N Sanders and Pieter Jan Stappers. 2008. Co-creation and the new landscapes of design. Co-design 4, 1 (2008), 5-18.
[36] Jesper Simonsen and Toni Robertson. 2012. Routledge international handbook of participatory design. Routledge.

[37] Aaron Smith. 2014. Older adults and technology use: Adoption is increasing, but many seniors remain isolated from digital life. Pew Research Center (2014).

[38] Lucy Suchman. 2007. Human-machine reconfigurations: Plans and situated actions. Cambridge University Press.

[39] John Vines, Rachel Clarke, Peter Wright, John McCarthy, and Patrick Olivier. 2013. Configuring participation: on how we involve people in design. In Proceedings of the SIGCHI Conference on Human Factors in Computing Systems. ACM, 429-438.

[40] John Vines, Gary Pritchard, Peter Wright, Patrick Olivier, and Katie Brittain. 2015a. An age-old problem: Examining the discourses of ageing in $\mathrm{HCI}$ and strategies for future research. ACM Transactions on Computer-Human Interaction (TOCHI) 22, 1 (2015), 2.

[41] John Vines, Peter C Wright, David Silver, Maggie Winchcombe, and Patrick Olivier. 2015b. Authenticity, Relatability and Collaborative Approaches to Sharing Knowledge about Assistive Living Technology. In Proceedings of the 18th ACM Conference on Computer Supported Cooperative Work \& Social Computing. ACM, 82-94.

[42] Jenny Waycott, Frank Vetere, Sonja Pedell, Lars Kulik, Elizabeth Ozanne, Alan Gruner, and John Downs. 2013. Older adults as digital content producers. In Proceedings of the SIGCHI Conference on Human Factors in Computing Systems. ACM, 39-48.

[43] Jenny Waycott, Frank Vetere, Sonja Pedell, Amee Morgans, Elizabeth Ozanne, and Lars Kulik. 2016. Not For Me: Older Adults Choosing Not to Participate in a Social Isolation Intervention. In Proceedings of the 2016 CHI Conference on Human Factors in Computing Systems. ACM, 745-757.

[44] Wiktoria Wilkowska and Martina Ziefle. 2009. Which factors form older adults' acceptance of mobile information and communication technologies? HCI and Usability for e-Inclusion (2009), 81-101.

[45] Stephanie Wilson, Mathilde Bekker, Peter Johnson, and Hilary Johnson. 1997. Helping and hindering user involvement-a tale of everyday design. In Proceedings of the ACM SIGCHI Conference on Human factors in computing systems. ACM, 178-185.

[46] Peter C Wright and John C McCarthy. 2015. The politics and aesthetics of participatory HCI. interactions 22, 6 (2015), 26-31.

[47] Mary Zajicek. 2007. Web 2.0: hype or happiness?. In Proceedings of the 2007 international cross-disciplinary conference on Web accessibility (W4A). ACM, 35-39. 